\title{
A prática artesanal guasquería na cidade de Jaguarão-RS
}

\author{
Artisanal practice guasquería in the city of Jaguarao-RS
}

\section{La pratica artesanal guasqueria en la ciudad de Yaguarón-RS}

\author{
Juliana Porto Machado ${ }^{1}$ \\ Dr. Ronaldo Bernadino Colvero ${ }^{2}$
}

\begin{abstract}
Resumo
Este artigo tem por objetivo discutir sobre os resultados parciais de pesquisa desenvolvida no âmbito do projeto $\mathrm{O}$ artesanato em couro cru, guasquería, é uma prática que se mantém na contemporaneidade. As técnicas de produção são manuais, o que a caracteriza como artesanato. Possui forte ligação com a zona rural, principalmente com as atividades equestres. Nosso objetivo principal busca compreender a produção e reprodução da prática artesanal em couro cru (guasquería) em Jaguarão-RS, buscando entender os motivos que levaram esses sujeitos sociais a produzirem guasquería. Descrevendo os relatos de vida considerando as obras desses guasqueiros/artesãos, identificando as técnicas de criação do modo de fazer dos guasqueiros/artesãos, observando se o artefato em couro cru (guasquería) é fonte de memória para a formação e afirmação das identidades dos guasqueiros/artesãos. A metodologia consisti em uma proposta etnográfica através de entrevista semiestruturada com 07 artesãos/guasqueiros. A pesquisa está em desenvolvimento inicial, na seleção de bibliografias, leituras e fichamentos, como também no processo de mapeamento das fontes, elemento essencial para obter-se o resultado final. Portanto, as conclusões da referente pesquisa ainda são preliminares.
\end{abstract}

Palavras-chave: Artesanato, Couro cru, Guasquería, Identidade, Memória, Tradição.

\section{Resumen}

El cuero crudo artesanal, guasquería, es una práctica que sigue siendo hoy en día. Las técnicas de producción son manuales, que lo caracteriza como un arte. Tiene fuertes vínculos con el campo, especialmente con las actividades ecuestres. Nuestro objetivo principal busca comprender la producción y reproducción de la práctica artesanal en cuero crudo (guasquería) en Jaguarao-RS, buscando entender las razones por las cuales estos sujetos sociales que producen guasquería. Al describir las historias de vida teniendo en cuenta las obras de estos guasqueiros / artesanos, identificando las técnicas de creación de la forma de hacer las guasqueiros / artesanos, observando el artefacto en cuero crudo (guasquería) es fuente de memoria para la formación y la afirmación de las identidades guasqueiros / artesanos. Los consisti metodología etnográfica en una propuesta a través de entrevistas semiestructuradas con 07 artesanos / guasqueiros. La investigación está en desarrollo temprano, la selección de bibliografías, lecturas y fichamentos, sino también en el proceso de traducción de las fuentes, esencial para obtener el resultado final. Por lo tanto, los resultados de la investigación relacionada es aún preliminar.

Palabras claves: Artesania, cuero crudo, Guasquería, identidade, memoria, tradición

\footnotetext{
${ }^{1}$ Mestranda em Memória e Patrimônio Cultural; Universidade Federal de Pelotas - UFPel, Pelotas, Rio Grande do Sul, Brasil. julianamachado@institutoconex.org
}

${ }^{2}$ Doutor em História; Universidade Federal de Pelotas - UFPel, Pelotas, Rio Grande do Sul, Brasil. rbcolvero@gmail.com 


\begin{abstract}
The craft rawhide, guasquería, is a practice that remains nowadays. Production techniques are manual, which characterizes it as a craft. It has strong links with the countryside, especially with equestrian activities. Our main objective seeks to understand the production and reproduction of craft practice in rawhide (guasquería) in Jaguarao-RS, seeking to understand the reasons why these social subjects to produce guasquería. Describing the life stories considering the works of these guasqueiros / artisans, identifying the techniques of creating the way of doing the guasqueiros / craftsmen, observing the artifact in rawhide (guasquería) is memory source for the formation and affirmation of identities guasqueiros / artisans. The methodology consisti in an ethnographic proposal through semistructured interviews with 07 artisans / guasqueiros. The research is in early development, the selection of bibliographies, readings and fichamentos, but also in the process of mapping the sources, essential to obtain the final result. Therefore, the findings of related research is still preliminary.
\end{abstract}

Keywords: Crafts, Rawhide, Guasquería, Identity, Memory, Tradition

\title{
1. Introdução
}

Este artigo ponderará sobre a pesquisa inicial desenvolvida no curso de mestrado do Programa de Pós-Graduação em Memória Social e Patrimônio Cultural da Universidade Federal de Pelotas, em torno do objetivo central que visa a compreensão da produção e reprodução da prática artesanal em couro cru (guasquería) em Jaguarão-RS.

Uma prática artesanal tem como característica fundamental para ser definida como tal, a utilização das mãos como ferramenta motor para a criação de peças diferenciadas. Assim, a guasquería é um ramo artesanal que trabalha com couro cru animal, etimologicamente vem da palavra huasca derivada da palavra quéchua que significa couro, assim surge a guasca e o indivíduo que pratica esta forma de artesanato é o guasqueiro, conhecido também como trançador ou sogueiro.

A guasquería possui sua origem ligada ao gado vacum, que surge com a colonização do continente latino americano no século $\mathrm{XV}$, pelos espanhóis e portugueses, quando trouxeram esses animais por meio de navios de carga, para explora-los como produtos voltados para a alimentação. No Estado do Grande do Sul, em meados do século XVI, os jesuítas que firmaram reduções nesse território e reuniram indígenas para serem catequizados, criavam gado bovino para alimentação, mas nesta época o consumo do couro também passa a ser valorizado economicamente. Ao serem expulsos, os jesuítas deixam seus rebanhos, que acabam por tornarem-se bravios, reproduzindo-se livremente (LUVIZOTTO, 2010).

Consequentemente esse gado passa a ser uma característica positiva para a ocupação desse espaço territorial. Com a chegada de imigrantes no século XVII começam a se construir pequenas propriedades voltadas para a pecuária e a agricultura. Já no século XVIII, quando as fazendas ganham espaço e o gado passa a ser confinado aos campos das grandes propriedades surge a necessidade de instrumentos equestres para auxiliar no manejo desses animais. E com 
a abundância de couro utiliza-se essa matéria prima para suprir essa demanda, criando-se cordas, freios, boleadeiras, rebenques e outros aparatos (GARCÍA, 2009).

Dessa forma, o desenvolvimento industrial não eliminou as técnicas e práticas manuais, mas possibilitou a facilitação dessas ao introduzir ferramentas mecanizadas que podem auxiliar na criação artesanal e aumentar a produção de mais objetos em menos tempo.

Para Jameson (2004), a modernidade é o período no qual a inovação tecnológica passou a ser indispensável à vida em sociedade. Então, modernidade e tecnologia são interdependentes. Os países passaram a buscar os mecanismos técnicos como geradores de mudanças sociais, culturais, políticas e econômicas.

No entanto, ao utilizar essas tecnologias facilitadoras acaba por transformar o artesanato em si, com a relação artesão e objeto. Na guasquería, existem máquinas industriais para cortar tentos (tiras de couro), para amaciar couro e outras, mas o que ainda predomina, no contexto jaguarenses, são as ferramentas criadas pelo próprio guasqueiro.

Nesse sentido, o confronto industrial/manual é patente. Assim, a guasquería é uma manifestação cultural que possui valor simbólico em suas técnicas de modo de fazer, logo, pode ser visto como um ofício popular com valor sociocultural. Cria novos objetos e/ou conserta objetos de uso cotidiano, mantendo estruturação de produção tradicional e contemporânea.

$\mathrm{O}$ artesão/guasqueiro torna se capaz de dominar as técnicas e os conhecimentos de trabalho manual para criação de seus objetos, utilizando de um olhar estético crítico de confecção e possuindo um sentido apurado que dá origem a peças singulares, que se diferem da produção mecanicista. A atividade de guasquería na cidade de Jaguarão (RS) apresenta diferentes facetas.

É uma prática de artesanato que utiliza ferramentas de criação rudimentares em seu aspecto e ao mesmo tempo sofisticadas, quando utilizadas para dar acabamento em uma obra. Visível apenas como tradicional, voltada apenas para atividades ligadas a animais no trabalho do campo.

Deve se perceber além desses aspectos, considerando que essa forma de expressão cultural adotada por alguns sujeitos, acaba por se torna elemento fundamental e modificador em suas vidas, podendo ser complemento de sustentabilidade financeira, vista como profissão, expressão de suas memórias na transmissão do saber/fazer.

Assim, surge alguns objetivos necessários como a verificação de como os guasqueiros/artesões aprenderam suas técnicas e criam suas obras, buscando entender os motivos que levaram esses sujeitos sociais a produzirem guasquería e também identificando 
se o artefato em couro (guasquería) é fonte de memória e sua importância para a formação e afirmação das identidades dos artesãos/guasqueiros.

O público alvo desta pesquisa serão 07 guasqueiros/artesãos que trabalham com essa atividade de artesanato em couro da cidade de Jaguarão/RS. Partindo do reconhecimento que a guasquería é uma atividade que possui técnica e estilo de criação, seu artefato final deve ser percebido como objeto que possui e transmite informações, para tanto deve se considerar o saber/fazer que origina a guasquería é que a mantém no contexto contemporâneo.

A metodologia adotada para a realização do objetivo proposto será pesquisa qualitativa de cunho etnográfico com base no método de entrevista semiestruturada e de observação participante. Como o auxílio de veículos de coletas de informação como fotografia, filmagem, gravações de áudio e diário de campo.

A abordagem etnografia foi escolhida, pois permite utilizar mais de um método para obtenção dos dados desejados. Como afirma Cavalcanti \& Moita Lopes (1991, p. 139), "estes tipos de dados adquire uma natureza intersubjetiva ao se levar em conta várias subjetividades ou várias maneiras de olhar para o mesmo objeto de investigação”.

A etnografia historicamente tem sua origem como metodologia de pesquisa na Antropologia no século XIX, de acordo com Uriarte (2012) neste período, predominava o estudo sobre a evolução do homem com foco nos povos primitivos. Então, as produções científicas antropológicas eram abastecidas de informações obtidas através de relatos de viajantes e de missionários que faziam parte de expedições. Consequentemente, os textos produzidos acabavam por ser nada mais que um reprodução etnocêntrica do estranhamento em relação ao outro diferente (URIARTE, 2012).

Já em meados do século XIX os antropólogos tornam-se participantes das expedições, inicia-se o processo do ir a campo, de perceber o outro em seu território. Em uma investigação para compreender a cultura dos grupos. No século XX o antropólogo Bronislaw Malinowski viveu alguns anos junto aos trobriandeses, na ilha de Trobiand (URIARTE, 2012). Tendo que aprender o idioma dessa comunidade, para possibilitar a convivência e assim compartilhar eventos do dia-dia. Construindo-se assim o método etnográfico em sua Obra Argonautas do Pacífico Ocidental de 1922 (PEIRANO, 2008).

Sendo que, a etnografia torna-se mais que uma técnica de ir a campo, de apenas visitar e conhecer outra cultura que se difere da do pesquisador, como afirma Zarharlick e Green (1991, p. 3): 
A etnografia é mais do que um conjunto de métodos, técnicas de coleta de dados, procedimentos de análise ou descrição de narrativas. É uma abordagem sistemática, teoricamente orientada para o estudo da vida diária de um grupo social, e que envolve uma fase de planejamento, uma fase de descoberta e uma terceira fase de apresentação dos resultados.

Nesse sentido, como aponta Ingold (2008) o pesquisador tem que estar preparado para manter-se em um contato direto com o grupo estudado, para construir uma observação concreta e completa, em uma combinação de sentidos, planejamento e resultados. Em um encontro de culturas diferentes que irão compor o mesmo espaço físico por um determinado período de tempo. Compartilhando saberes, em um exercício de compreensão entre pesquisador e pesquisado (MAGNANI, 2009).

Ocorrendo a estimulação do uso dos sentidos, ao exercitar o ouvir/escutar e o olhar observador livre de críticas, possibilitando ao pesquisador realizar um movimento de deslocamento de seu espaço cultural conhecido e seguro, para o meio sociocultural do sujeito/objeto a ser analisado, em uma ação participativa de tempo determinado (MARCONI \& PRESOTTO, 2011).

A etnografia, como afirma Geertz (2008) é criar relações em meio a informações que se desencontram, em um contexto que apresenta linguagem própria, transitória e desconhecida ao olhar do pesquisador. Em observação densa e detalhada em meio fatos sociais que acontecem a todo tempo e que são interpretados (pelo observado) e reinterpretados (pelo observador). Em uma busca por compreender a cultura do outro (GEERTZ,2008).

A partir disso, a pesquisa será realizada através de entrevistas semiestruturadas aberta com 07 guasqueiros/artesãos da cidade, conhecendo a histórias de vida a partir do "olhar" desse sujeito objeto da pesquisa, os feitos e principalmente a transmissão do saber/fazer guasquería por meio de relatos pessoais, coletando esses dados individualmente com cada sujeito pesquisado, guiando se pelo roteiro semiestruturado contento algumas categorias de análises principais da pesquisa como os relatos de vida, as técnicas tradicionais/contemporâneas, transmissão do saber/fazer, o meio urbano/rural e memória/identidade do guasqueiro.

Para macdougall (2006), a imagem fotográfica permite ao operador do instrumento fotográfico (pesquisador) refletir sobre as igualdades e as diferenças entre o eu pesquisador e o outro pesquisado. A cultura retratada na imagem, conduz a uma reflexão sobre a realidade de fatos vividos e interpretados por essa comunidade observada.

\section{Discussão}


O artesanato no Estado do Rio Grande do Sul possui forte ligação com os povos indígenas que habitavam esse território. Os mesmos utilizavam os recursos naturais para confeccionar objetos de uso do cotidiano, moradias, vestimentas e ferramentas de caça. Com a colonização da América Latina no século XV pelos europeus, principalmente espanhóis e portugueses, houve a morte de muitos indígenas reduzindo-os a poucos (LUVIZZOTO, 2010). O uso de matérias primas naturais foi transmitido e aperfeiçoado ao logo do tempo.

O artesanato segundo Keller (2014) pode ser definido como algo heterogêneo, é uma expressão cultural que está entre a tradição e a modernidade. Seu grau de valorização se apresenta pela característica de ser meio de inclusão sociocultural, uma vez que, é uma profissão, um condutor de desenvolvimento local e de valor imaterial. É uma atividade de produção manual exercido em sua grande parte por grupos sociais familiares de forma informal como uma complementação de renda (KELLER, 2014).

Um ofício cujo exercício manual é o mecanismo central, tendo em vista a importância do pessoal do trabalho do artesão e de suas mãos em detrimento ao capital econômico; porque todo o artefato artesanal por si só se torna um compilado da destreza, do conhecimento e da técnica de seu produtor (ROTMAN, 2013).

O artesanato é um bem cultural imaterial, de acordo com Bialogorski (2005), este não pode ser percebido apenas em sua materialidade, um mero objeto sem discurso, posto que é sua riqueza imaterial que o faz visível e capaz de transmitir informações em dimensões estéticas, de saber/fazer, de técnicas, de símbolos e de identidades.

Para Rotman (pg. 147, 2013) “o artesanato possui uma dimensão patrimonial; expressa características significativas para a compreensão da vida dos diferentes grupos humanos. Assim, compromete múltiplos aspectos de sua realidade histórica, econômica e sociocultural”, em uma relação contínua com os âmbitos sociais, políticos e econômicos (CANCLINI,1983). Em vista disso, o artesanato em couro cru denominado guasquería (Figura-01) é uma prática de produção popular com elementos do tradicional da região sul da América Latina.Tasso (2001) ressalta:

Hoy los objetos producidos por el guasquero son apropiados desde diferentes lugares, a nivel local, como objetos de tradición e identidad y, desde un consumo no local, como objetos singularizados: por sus cualidades técnicas, estéticas y de representación de una cultura (TASSO, 2001, p. 45).

Para Romero (2010) as técnicas da guasquería deveriam ser detalhadamente investigadas, para compreender como ocorre a transmissão do saber/fazer deste ofício secular. 


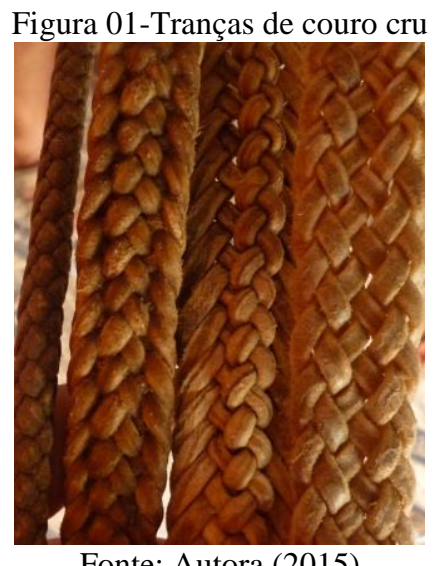

O fato de existir poucos registros dessa atividade por parte dos historiadores, demonstrando o quanto essa manifestação artesanal foi prejudicada ao longo do tempo (GARCÍA, 2009). Mas a ligação da guasquería com as atividades de pecuária, equestres e também com o sujeito sociocultural tradicional representativo da região sul, o gaúcho ${ }^{3}$, foi o que possibilitou a sua existência até os tempos atuais (TASSO, 2001).

Uma vez que, quando acontecimentos não possuem mais suporte de grupos sociais e se perdem em memórias individuas e fragmentadas os mesmos não encontram espaço para se manifestarem frente ao progresso cultural. O suporte é um importante mecanismo localizador de memórias, é a partir dele que o sujeito social pode relembrar e assim reforçar sua identidade (HALBWACHS, 2004).

Para Candau (2011), a identidade é criada socialmente a partir das interações, das trocas de saberes e das relações, que fazem com que se estabeleça um vínculo, uma sensação de reconhecimento e de afinidade com certos contextos, objetos, símbolos e sujeitos. A partir disso, não existe uma única identidade íntegra, autêntica e autônoma (HALL, 2003).

\footnotetext{
${ }^{3}$ Joseph Love na obra O Regionalismo Gaúcho (1975), define gaúcho como o homem livre, nômade, bruto, sem paragens. Cruzava os campos do pampa, mestre na arte de montas e domas de animais. Muitas vezes considerado alguém perigoso, desertor. Seus hábitos culturais são uma mescla dos hábitos indígenas com o dos europeus.
} 
Sendo que, a identidade, por sua vez, possui uma relação de dependência com a memória, uma beneficia a outra mutuamente produzindo uma história, segundo Candau (2011) a memória tem como tarefa relembrar o passado, mas pode ser remodelada pelos indivíduos, o esquecimento é a válvula de escape, o local de descarte das lembranças quando essas se tornam penosas ou causam a separação dos grupos sociais.

Possuímos memórias sociais que se manifestam automaticamente, que não exigem um exercício forte de evocação, são hábitos, gestos, linguagem corporal/oral/escrita, não precisa realizar uma reflexão analítica (CANDAU, 2011). Assim, uma tradição para ser transmitida precisa fixar signos, tem a capacidade de criar estruturas facilmente memoráveis, como afirma Candau (2011), as tradições só acabam quando as memórias são impossibilitadas de variações interpretativas, não podendo ser mais compartilhadas. Se conservam por meio de memória forte coesa e coerente que organiza os grupos.

Então toda tradição é uma invenção, se manifesta por meio de ritos e costumes ligados a certos elementos do passado. Contudo, só é criada quando práticas antigas se dissolvem e se perdem. Nesse caso, os sujeitos possuem a necessidade de inventarem uma nova tradição (HOBSBAWM E RANGER, 1984). Mas a tradição muitas vezes esquecida, sem suporte para se manifestar passa por uma retradicionalização, como afirma Machuca (2010) uma atualização, uma modernização da reativação de hábitos e costumes culturais já desaparecidos, fazendo com que se tornem atuantes novamente.

Todavia, Lenclud (2005) considera três elementos intrínsecos a tradição, causadores de conflitos como a conservação no tempo, em uma ausência de mudança por partes das práticas tradicionais, seguindo o padrão original idêntico. Fato deveras conflitante uma vez que no contexto social as modificações estão sempre atuando. E que a tradição para se conserva, deve se adaptar.

Logo, tem-se a mensagem cultural, a qual a tradição está presente nas ideias, no imaterial, no intangível. Não apenas nas representações, nos gestos e nos ritos. Pois, o hábito de comer tem toda uma ritualização, mas não é considerado uma tradição. Já ativação cultural seria percebe que a tradição não é algo estruturado, fixado no passado, totalmente pronta, ao contrário ela se constrói do presente em direção ao passado. Uma vez que, o passado é reinterpretado no presente (LENCLUD, 2005).

\section{Conclusões}

O objeto desse trabalho encontra suporte na sociedade atual através da valoração do artesanato, que permeia o campo social e o simbólico, lhe permitindo ser um meio de criação 
em que o indivíduo pode usar de todo o seu saber/fazer, de suas técnicas de produção e estilismo.

\section{Referências}

BIALOGORSKI, Mirta. Patrimoniointangible: Reflexiones sobre suconsideración como fenómeno. Buenos Aires: Comisión para laPreservación del PatrimonioHistórico Cultural de laCiudad de Buenos Aires, 2005.

CAVALCANTI, M. C.; MOITA LOPES, L. P. Implementação de pesquisa na sala de aula de línguas no contexto brasileiro. Trabalhos de Linguística Aplicada, Campinas, SP: Unicamp, v.17, p. 133-144, Jan. / Jun, 1991.

CANCLINI, Nestor G. As culturas populares no capitalismo. São Paulo: Brasiliense, 1983.

CANDAU, Joel. Memória e identidade. Tradução: Maria Leticia Ferreira. São Paulo: Contexto, 2011.CHIZZOTTI, Antônio. Pesquisas em Ciências Humanas e Sociais. São Paulo: Cortez, 1991.

GARCÍA, Rocío. De la yerra a la Vitrina: Transformaciones contemporáneas de la guasquería. Montevideo: Trama Revista de Cultura y Patrimonio. ano 1, nº 1, setembro 2009.

GEERTZ, Clifford. A Interpretação das Culturas. Rio de Janeiro: LTC, 2008.

GIDDENS, Anthony. As consequências da modernidade. Tradução de Raul Fiker. São Paulo: UNESP, 1991.

HALBWACHS, Maurice. A Memória Coletiva. São Paulo: Ed. Centauro, 2004.

HALBWACHS, Maurice. Los marcos sociales de la memoria. Caracas: Anthropos Editorial, 2004.

HALL, Stuart. Da diáspora: Identidades e mediações culturais. Belo Horizonte: Editora UFMG, 2003.

HOBSBAWM, Eric \& RANGER, Terence. A Invenção das Tradições. Rio de Janeiro:Paz e Terra, 1984.

INGOLD, T. Anthropology is not Ethnography. Proceedings of the British Academy, 154, 2008. 69-92.

MAGNANI, J. De perto e de dentro: notas para uma etnografia urbana. Revista Brasileira de Ciências Sociais, São Paulo, 17, jul. 2002. 11-29. MAGNANI, J. Etnografia como prática e experiência. Horizontes Antropológicos, Porto Alegre, 15, n. 32, jul./dez. 2009. 129-156.

JAMESON, Frederic. Una modernidad singular: Ensayo sobre la ontologia del presente. Barcelona; Gedisa; 2004. 
LENCLUD, Gerard. La tradicion nést plus ce quélle était. Terrain, 2005.

LOVE, Joseph. O regionalismo gaúcho. São Paulo: Perspectiva, 1975.

LUVIZOTTO, Caroline. As Tradições No Contexto Da Modernidade: Reflexividade E Ludicidade - O Caso Das Tradições Gaúchas. Anais do II Simpósio de Pesquisa de Pósgraduandos em Sociologia da USP, UNICAMP, UFSCAR, UFRJ e UNESP. São Paulo: USP, 2009.

MACDOUGALL, David. The visual in Anthropology. In. The corporeal image. Film, ethnography and the senses. Princeton, New Jersey, Princeton University Press, 2006.

MACHUCA, Jésus A. Patrimonio y retradicionalizacion em la cultura indígena y popular em México In: FERREIRA, M.Letícia; MICHELON, Francisca. Memoria, patrimônio e Tradição. Pelotas: Edufpel, 2010.

MARCONI, Marina de Andrade; PRESOTTO, Zelia Maria Neves. Antropologia: Uma Introdução. São Paulo: Atlas, 2011.

PEIRANO, M. Etnografia, ou a teoria vivida. PontoUrbe, 2, fevereiro 2008.

ROMERO, Sonnia. Patrimonio Cultural Inmaterial del Uruguay. Montevideo: Comisión de Patrimonio Cultural de la Nación - Ministerio de Educación y Cultura, 2010.

ROTMAN, Mónica. Lasmúltiples y ComplejasArticulaciones entre los Campos del Patrimonio y de lasArtesanías. In: Diversidade Cultural y Estado: Escenários y desafios de hoy. Argentina: Primer Encuentro Nacional de Patrimonio Vivo, 2015.

THOMPSON, E.P. Costumes em comum - Estudos sobre cultura popular tradicional. São Paulo: Companhia das letras, 1998.

TASSO, Alberto. Teleras y sogueros. La artesanía tradicional de Santiago del Estero entre la cultura, la historia y el mercado. Buenos Aires: V Congreso Nacional de Estudios del Trabajo, 2001.

URIARTE, U. M. O que é fazer etnografia para os antropólogos. Ponto Urbe, 6, dezembro 2012.

ZARHARLICK, A.; GREEN, J. Ethnographic research. In: FLOOD, J. et al. (Eds.). Handbook of research in teaching the English Language Arts. New York: Macmillan, 